Discussion Paper No. 972

\title{
NON-MANIPULABILITY \\ OF WALRASIAN MECHANISMS \\ IN ECONOMIES \\ WITH A LARGE NUMBER OF OBJECTS
}

\author{
Tomoya Tajika \\ Tomoya Kazumura
}

May 2016

The Institute of Social and Economic Research

Osaka University

6-1 Mihogaoka, Ibaraki, Osaka 567-0047, Japan 


\title{
Non-manipulability of Walrasian mechanisms in economies with a large number of objects*
}

\author{
Tomoya Tajika ${ }^{\dagger} \quad$ Tomoya Kazumura ${ }^{\ddagger}$
}

May 27, 2016

\begin{abstract}
We consider a problem of allocating multiple identical objects to a group of agents and collecting payments. Each agent may receive several objects and has quasi-linear preferences with a submodular valuation function. It is known that Walrasian mechanisms are manipulable. We investigate the incentive property of Walrasian mechanisms in economies with a large number of objects. Given a set of agents and a preference profile, an agent $i$ asymptotically dominates an agent $j$ if at sufficiently many objects, $i$ 's incremental valuation is higher than $j$ 's incremental valuation. We show that for each economy, if there is no agent asymptotically dominating the other agents, and if there are sufficiently many objects, any Walrasian mechanism is non-manipulable at the economy.

We also consider replica economies, and show that for each economy, if it is replicated sufficiently many times, the minimum price Walrasian mechanisms are non-manipulable at the replica economy.

Keywords. Non-manipulability, Walrasian mechanism, Vickrey mechanism, asymptotic domination, replica economy, submodular preferences

JEL Classification Numbers. D44, D71, D61, D82

*The authors are grateful to Anup Pramanik, Abdul Quadir, and Yu Zhou for helpful comments. The authors acknowledge the financial support from the Japan Society for the Promotion of Science (Tajika, 14J05350; Kazumura, 14J05972).

${ }^{\dagger}$ Graduate School of Economics, Kobe University, 2-1 Rokkodai-cho, Nada-ku, Kobe, 657-8501, Japan. Email: tomoyatajika@gmail.com

${ }^{\ddagger}$ Graduate School of Economics, Osaka University 1-7 Machikaneyama, Toyonaka, Osaka 560-0043, Japan. Email: pge003kt@ student.econ.osaka-u.ac.jp
\end{abstract}




\section{Introduction}

Auctions are often conducted to efficiently allocate objects such as spectrum licenses, public houses, treasury bills, etc. The Walrasian mechanism is an auction often studied in the literature. ${ }^{1}$ Under truthful reporting, the Walrasian mechanism selects an efficient allocation. ${ }^{2}$ However, the Walrasian mechanism turns out to be manipulable: some agent has an incentive to misreport his preferences. Such manipulability leads Walrasian mechanisms to select an inefficient allocation (Ausubel et al., 2014; Baisa, 2015).

In the auction theory literature, some authors focus on large economies where there are many agents and possibly many objects, and investigate whether the incentive issues and inefficiency of Walrasian mechanism are resolved. For example, Swinkels (2001), Jackson and Kremer (2006), and Bodoh-Creed (2013) consider (Bayesian) Nash equilibria and show that under different assumptions on preferences, equilibria of Walrasian mechanisms arbitrarily close to efficient as the number of agents and possibly that of objects go to infinity. Azevedo and Budish (2015) show that truth-telling is asymptotically optimal against any full support distribution of the other agents' preferences.

In reality, however, there are situations in which there are many objects while the number of agents is relatively small. For example, in FCC's AWS-3 auction, there are nearly 1600 objects while there are only 70 bidders. $^{3}$ To the best of our knowledge, few papers in the literature on auction theory focus on such situations.

We investigate non-manipulability of Walrasian mechanisms for the cases in which there are sufficiently many identical objects. In our paper, each agent is assumed to have quasi-linear preferences with a submodular valuation function. First we show that even if there are sufficiently many objects, a Walrasian mechanism is manipulable (Example 1).

A feature of Example 1 is that there is an agent such that at sufficiently many objects, his incremental valuation is higher than any other agents' incremental valuations. We say that a preference profile satisfies no asymptotic domination if there is no such agent. We show that if no asymptotic domination is satisfied and there are sufficiently many objects,

\footnotetext{
${ }^{1}$ In auction theory, this auction format is sometimes called a uniform price auction.

${ }^{2}$ The Walrasian mechanism also satisfies some other desirable properties under truthful reporting such as no-envy (Foley, 1967) and individual rationality.

${ }^{3}$ See Auction 97 summary, FCC, available at http://wireless.fcc.gov/auctions/default. htm?job=auction_summary\&id=97.
} 
then each Walrasian mechanism is non-manipulable.

We also consider the case where both the number of agents and that of objects are sufficiently large. In particular, we study replica economies. First, we show that some Walrasian mechanism is manipulable at any replica of an economy (Example 2). The minimum price Walrasian mechanism is a Walrasian mechanism that assigns a minimum price Walrasian equilibrium allocation for each preference profile. Finally, we show that for each economy, if it is replicated sufficiently many times, each minimum price Walrasian mechanism is non-manipulable at the replica economy.

\subsection{Related literature}

Several papers in auction theory study large auctions. Most of them focus on some specific auction(s). For example, Swinkels (2001), Jackson and Kremer (2006), and BodohCreed (2013) consider Walrasian mechanisms, Swinkels (1999, 2001) and Jackson and Kremer (2006) consider discriminatory auctions, ${ }^{4}$ and Cripps and Swinkels (2006) and Fudenberg et al. (2007) consider double auctions. On the other hand, Azevedo and Budish (2015) consider a general large market model including a variety of models such as auction model, matching model, etc.

The most related papers to ours are Swinkels (2001), Jackson and Kremer (2006), Bodoh-Creed (2013), and Azevedo and Budish (2015). However, there are several differences between our paper and these four papers. First, our paper and these four papers focus on different types of large economies. As we have mentioned, these four papers focus on cases in which there are sufficiently many agents. On the other hand, we focus on cases in which there are sufficiently many objects.

Second, the allocation achieved as an equilibrium and agents' incentives in large economies in our paper are different from those in the four papers. Swinkels (2001), Jackson and Kremer (2006), Bodoh-Creed (2013) achieve an approximately efficient allocation as a (Bayesian) Nash equilibrium, while our result is interpreted as the result that an (exactly) efficient allocation is achieved as a Nash equilibrium when the realized preference profile satisfies no asymptotic domination. Azevedo and Budish (2015) consider

\footnotetext{
${ }^{4}$ The discriminatory auction is an auction such that the object allocation is determined in order that the sum of valuations is maximized, and each agent pays the valuation for the objects he obtains.
} 
a notion called strategy-proofness in the large, which requires that in large economies, truth-telling should be approximately optimal against any full support distribution of the other agents' preferences. On the other hand, our result implies that in large economies, truth-telling is (exactly) optimal against any distribution of the other agents' preferences such that preference profiles consisting of his true preference relation and the other agents' preferences in the support of the distribution satisfy no asymptotic domination.

Third, these four papers make an assumption that each agent demands up to some fixed unit of objects. In our model, this assumption implies that at some point, the incremental valuation of each agent becomes zero. Thus, in our model with this assumption, if there are sufficiently many objects, then the prices given by Walrasian mechanisms are zero, and this implies that no agent can benefit from misreporting their preferences. Hence, under the assumption, our result becomes trivial. Thus, we do not make the assumption.

There are also papers focusing on large markets in a variety of models such as classical exchange economy (Roberts and Postlewaite, 1976; Otani and Sicilian, 1982, 1990; Jackson and Manelli, 1997), matching model (Immorica and Mahdian, 2005; Kojima and Pathak, 2009; Che and Kojima, 2010; Che et al., 2015; Che and Tercieux, 2015; Lee, 2015), etc.

This article is organized as follows. In Section 2, we introduce the model and definitions. In Section 3, we define the Vickrey and the Walrasian mechanisms, and state several facts on the mechanisms. We state the main result in Section 4. In Section 5, we consider replica economies and state a result. All the proofs appear in Appendix.

\section{Preliminary and Definitions}

We consider economies with arbitrary finite number of agents and arbitrary finite number of identical objects. Each "potential" agent is indexed by a natural number $i \in \mathbb{N}$. Let $\mathcal{N}$ be the class of finite subset of $\mathbb{N}$ with more than one element. Let $X:=\mathbb{N} \cup\{0\}$. A typical (consumption) bundle of agent $i \in \mathbb{N}$ is a pair $z_{i}:=\left(x_{i}, t_{i}\right) \in X \times \mathbb{R}$, where $x_{i}$ denotes the number of objects agent $i$ receives and $t_{i}$ denotes his payment. Thus, the consumption set is $X \times \mathbb{R}$.

Each agent $i \in \mathbb{N}$ has a complete and transitive preference relation over $X \times \mathbb{R}$. The 
strict and indifference relations associated with $R_{i}$ are denoted by $P_{i}$ and $I_{i}$, respectively. We assume that each preference relation $R_{i}$ satisfies the following conditions.

QUASI-LINEARITY: There is a valuation function $v_{i}: X \rightarrow \mathbb{R}_{+}$such that $v_{i}(0)=0$ and for each pair $\left(x_{i}, t_{i}\right),\left(x_{i}^{\prime}, t_{i}^{\prime}\right) \in X \times \mathbb{R},\left(x_{i}, t_{i}\right) R_{i}\left(x_{i}^{\prime}, t_{i}^{\prime}\right)$ if and only if $v_{i}\left(x_{i}\right)-t_{i} \geq v_{i}\left(x_{i}^{\prime}\right)-t_{i}^{\prime}$.

Monotonicity: For each pair $x_{i}, x_{i}^{\prime} \in X$, if $x_{i}<x_{i}^{\prime}, v_{i}\left(x_{i}\right) \leq v_{i}\left(x_{i}^{\prime}\right)$.

Submodularity: For each pair $x_{i}, x_{i}^{\prime} \in X$, if $x_{i}<x_{i}^{\prime}, v_{i}\left(x_{i}+1\right)-v_{i}\left(x_{i}\right) \geq v_{i}\left(x_{i}^{\prime}+1\right)-v_{i}\left(x_{i}^{\prime}\right)$.

INTEGER VALUES: For each $x_{i} \in X, v_{i}\left(x_{i}\right) \in \mathbb{N} \cup\{0\} .^{5}$

Let $\mathcal{R}$ be the class of preferences satisfying the four conditions just defined. An economy is a tuple $e:=(N, R, \bar{x}) \in \mathcal{N} \times \bigcup_{n \in \mathbb{N}} \mathcal{R}^{n} \times X$ such that $R \in \mathcal{R}^{|N|}$. Let $\mathcal{E}$ denote the class of economies. Given $N \in \mathcal{N}, R \in \mathcal{R}^{|N|}$, and $i \in N$, we denote $N_{-i}:=N \backslash\{i\}$ and $R_{-i}:=\left(R_{j}\right)_{j \neq i}$.

Let $e:=(N, R, \bar{x}) \in \mathcal{E}$. An object allocation for $e$ is a tuple $x:=\left(x_{i}\right)_{i \in N} \in X^{|N|}$ such that $\sum_{i \in N} x_{i} \leq \bar{x}$. We denote the set of object allocations for $e$ by $A(e)$. A (feasible) allocation for $e$ is a tuple $z:=\left(z_{i}\right)_{i \in N}:=\left(\left(x_{i}, t_{i}\right)\right)_{i \in N} \in(X \times \mathbb{R})^{|N|}$ such that $\left(x_{i}\right)_{i \in N} \in A(e)$. We denote the set of allocations for $e$ by $Z(e)$. Given $x:=\left(x_{i}\right)_{i \in N} \in A(e)$ and $t:=\left(t_{i}\right)_{i \in N} \in \mathbb{R}^{n}$, we may write $(x, t)$ to mean the allocation $\left(\left(x_{i}, t_{i}\right)\right)_{i \in N}$.

A mechanism is a mapping $f: \mathcal{E} \rightarrow \bigcup_{e \in \mathcal{E}} Z(e)$ such that for each $e \in \mathcal{E}, f(e) \in Z(e)$. For each $e:=(N, R, \bar{x}) \in \mathcal{E}$ and each $i \in N, f_{i}(e)$ denotes the bundle assigned to agent $i$, and we write $f_{i}(e)=\left(x_{i}(e), t_{i}(e)\right)$, where $x_{i}(e)$ is the number of objects that agent $i$ receives and $t_{i}(e)$ is his payment. For each $e:=(N, R, \bar{x}) \in \mathcal{E}$, we also write $x(e):=\left(x_{i}(e)\right)_{i \in N}$ and $t(e):=\left(t_{i}(e)\right)_{i \in N}$.

We now introduce properties of mechanisms. The first property states that for each economy, a mechanism selects an efficient allocation. Given $e:=(N, R, \bar{x}) \in \mathcal{E}$, an allocation $(x, t) \in Z(e)$ is efficient for $e$ if $\sum_{i \in N} v_{i}\left(x_{i}\right)=\max _{x^{\prime} \in A(e)} \sum_{i \in N} v_{i}\left(x_{i}^{\prime}\right){ }^{6}$ Note that this

\footnotetext{
${ }^{5}$ Our results hold even if this assumption is weakened as follows: there is $\delta \in \mathbb{R}$ such that for each $x_{i} \in X, v_{i}\left(x_{i}\right) \in\{r \in \mathbb{R}: \exists m \in \mathbb{N}$ s.t. $r=m \cdot \delta\}$.

${ }^{6}$ In the literature, this notion is sometimes called decision efficiency.
} 
definition does not impose any condition on payment. Thus, given $e \in \mathcal{E}$, we also say that an object allocation $x \in A(e)$ is efficient for $e$ if $\sum_{i \in N} v_{i}\left(x_{i}\right)=\max _{x^{\prime} \in A(e)} \sum_{i \in N} v_{i}\left(x_{i}^{\prime}\right)$. Given $e \in \mathcal{E}$, let $P(e)$ be the set of efficient object allocations for $e$.

Remark 1. Let $e=(N, R, \bar{x}) \in \mathcal{E}$. Suppose that there is $i \in N$ such that for each $x_{i} \in X$ with $x_{i}<\bar{x}, v_{i}\left(x_{i}+1\right)-v_{i}\left(x_{i}\right)>0$. Then, for each $x \in P(e), \sum_{j \in N} x_{j}=\bar{x}$.

Remark 2. Let $e:=(N, R, \bar{x}) \in \mathcal{E}$ and $x \in P(e)$. Let $i \in N$, and $j \in N \backslash\{i\}$ be such that $x_{j}>0$. Then, $v_{i}\left(x_{i}+1\right)-v_{i}\left(x_{i}\right) \leq v_{j}\left(x_{j}\right)-v_{j}\left(x_{j}-1\right)$.

EFFICIENCY: For each $e \in \mathcal{E}, f(e)$ is efficient for $e$.

Next we introduce notions of incentive compatibility. The following property states that at an economy, there is an agent who benefits from reporting false preferences.

Manipulability at $e:=(N, R, \bar{x}) \in \mathcal{E}$ : There are $i \in N$ and $e^{\prime}:=\left(N,\left(R_{i}^{\prime}, R_{-i}\right), \bar{x}\right) \in \mathcal{E}$ such that $f_{i}\left(e^{\prime}\right) P_{i} f_{i}(e)$.

The following property states that at an economy, each agent does not benefit from reporting false preferences.

Non-Manipulability at $e:=(N, R, \bar{x}) \in \mathcal{E}: f$ is not manipulable at $e$.

The following property requires that the mechanism be non-manipulable at each economy.

StrategY-PRoOfNESS: $f$ is non-manipulable at each $e \in \mathcal{E}$. 


\section{Vickrey and Walrasian mechanisms}

In this section we define the Vickrey and the Walrasian mechanisms, and states facts related to the mechanisms.

Definition 1. A mechanism $f=(x, t)$ is a Vickrey mechanism if for each $e:=(N, R, \bar{x}) \in$ $\mathcal{E}$

$$
x(e) \in \underset{y \in A(e)}{\arg \max } \sum_{i \in N} v_{i}\left(y_{i}\right)
$$

and for each $i \in N$,

$$
t_{i}(e)=\max _{y \in A(e)} \sum_{j \in N_{-i}} v_{j}\left(y_{j}\right)-\sum_{j \in N_{-i}} v_{j}\left(x_{j}(e)\right)
$$

It is known that Vickrey mechanisms are efficient and strategy-proof.

Next, we define the Walrasian mechanism. Let $p \in \mathbb{R}_{+}$be a price, and let $\bar{x} \in X$. The budget set at $p$ and $\bar{x}$ is defined as $B(p, \bar{x}):=\left\{\left(x_{i}, t_{i}\right) \in X \times \mathbb{R}: x_{i} \leq \bar{x}\right.$ and $\left.t_{i}=p \cdot x_{i}\right\}$. Given $R_{i} \in \mathcal{R}$, the demand set at $p$ and $\bar{x}$ for $R_{i}$ is defined as $D\left(R_{i}, p, \bar{x}\right):=\left\{x_{i} \in X: x_{i} \leq\right.$ $\bar{x}$ and $\left.\forall z_{i}^{\prime} \in B(p, \bar{x}),\left(x_{i}, p \cdot x_{i}\right) R_{i} z_{i}^{\prime}\right\}$.

Definition 2. Given $e:=(N, R, \bar{x}) \in \mathcal{E}$, a pair $((x, t), p) \in Z(e) \times \mathbb{R}_{+}$is a Walrasian equilibrium for $e$ if

WE-i: for each $i \in N,\left(x_{i}, t_{i}\right) \in B(p, \bar{x})$ and $x_{i} \in D\left(R_{i}, p, \bar{x}\right)$, and WE-ii: if $p>0$, then $\sum_{i \in N} x_{i}=\bar{x}$.

Condition WE-i states that each agent receives the amount of objects that he demands, and the bundle is in the budget set. Condition WE-ii states that if the price is positive, then all the objects are assigned. Given $e \in \mathcal{E}$, let $W(e)$ be the set of Walrasian equilibria for $e$, and let

$$
\begin{aligned}
& Z^{W}(e):=\left\{z \in Z(e): \text { for some } p \in \mathbb{R}_{+},(z, p) \in W(e)\right\}, \text { and } \\
& P^{W}(e):=\left\{p \in \mathbb{R}_{+}: \text {for some } z \in Z(e),(z, p) \in W(e)\right\} .
\end{aligned}
$$


That is, $Z^{W}(e)$ is the set of Walrasian equilibrium allocations for $e$, and $P^{W}(e)$ is the set of Walrasian equilibrium prices for $e$.

In general, a Walrasian equilibrium may not exist. ${ }^{7}$ However, if preferences are quasilinear and submodular, a Walrasian equilibrium always exists.

Fact 1 (Kelso and Crawford, 1982). For each $e \in \mathcal{E}$, a Walrasian equilibrium for e exists. ${ }^{8}$

Moreover, for quasi-linear and submodular preferences, there are minimum and maximum Walrasian equilibrium prices.

Fact 2 (Gul and Stacchetti, 1999). For each $e \in \mathcal{E}$, there are $p \in P^{W}(e)$ and $p^{\prime} \in P^{W}(e)$ such that for each $p^{\prime \prime} \in P^{W}(e), p \leq p^{\prime \prime} \leq p^{\prime}$.

Given $e \in \mathcal{E}$, let $Z_{\min }^{W}(e)$ and $Z_{\max }^{W}(e)$ be the sets of minimum and maximum price Walrasian equilibrium allocations for $e$, respectively, and let $p_{\min }(e)$ and $p_{\max }(e)$ denote the minimum and maximum Walrasian prices for $e$, respectively.

Walrasian equilibrium allocations are efficient. Furthermore, efficient object allocation are supported by any Walrasian equilibrium prices.

Fact 3 (Gul and Stacchetti, 1999). Let $e=(N, R, \bar{x}) \in \mathcal{E}, x \in A(e)$, and $p \in P^{W}(e)$. Then, $x \in P(e)$ if and only if $\left(\left(x_{i}, p \cdot x_{i}\right)\right)_{i \in N} \in Z^{W}(e)$.

Definition 3. A mechanism $f$ is a Walrasian mechanism if for each $e \in \mathcal{E}, f(e) \in Z^{W}(e)$. A mechanism $f$ is a minimum (resp. maximum) price Walrasian mechanism if for each $e \in \mathcal{E}, f(e) \in Z_{\min }^{W}(e)\left(\right.$ resp. $\left.f(e) \in Z_{\max }^{W}(e)\right)$.

By Fact 3, Walrasian mechanisms satisfy efficiency. However, they are not strategyproof. $^{9}$

\footnotetext{
${ }^{7} \mathrm{Gul}$ and Stacchetti (1999) show that, allowing heterogeneity of objects, if a preference relation violates the so-called "gross substitutes" condition, there is an economy where an agent has the preference relation, the other agents have gross substitutes preferences, and a Walrasian equilibrium does not exists.

${ }^{8}$ Precisely, Kelso and Crawford (1982) consider the model where objects can be heterogeneous. They show that if preferences satisfy the gross substitutes condition, a Walrasian equilibrium exists. Our model is interpreted as a special case of their model where each agent has a submodular valuation function, and, given a payment level, each agent finds sets of objects with the same cardinality indifferent. It is known that such preferences satisfy the gross substitutes condition, and hence, Fact 1 holds. The same argument holds for Facts 2, 3, and 4.

${ }^{9}$ See Example 1 in Section 4.
} 
The following proposition shows the characterizations of the minimum and maximum Walrasian equilibrium prices. ${ }^{10}$

Proposition 1 (Gul and Stacchetti, 1999). Let $e:=(R, N, \bar{x}) \in \mathcal{E}$, and $x \in P(e)$. Then,

(i) $p_{\min }(e)=\max \left\{v_{i}\left(x_{i}+1\right)-v_{i}\left(x_{i}\right): i \in N\right.$ and $\left.x_{i} \neq \bar{x}\right\}$, and

(ii) $p_{\max }(e)=\min \left\{v_{i}\left(x_{i}\right)-v_{i}\left(x_{i}-1\right): i \in N\right.$ and $\left.x_{i} \neq 0\right\}$.

Finally, the following states that if a Walrasian mechanism and a Vickrey mechanism share the same object allocation function, the payment of an agent under the Walrasian mechanism is no less than his payment under the Vickrey mechanism.

Fact 4 (Gul and Stacchetti, 1999). Let $f=(x, t)$ be a Walrasian mechanism and $g=(x, s)$ a Vickrey mechanism. For each $e:=(N, R, \bar{x}) \in \mathcal{E}$ and each $i \in N, t_{i}(e) \geq s_{i}(e)$.

\section{Main results}

We study incentive properties of Walrasian mechanisms when there are many objects. The following proposition is a sufficient condition for a Walrasian mechanism to be nonmanipulable at an economy.

Proposition 2. Let $f=(x, t)$ be a Walrasian mechanism and $g=(x, s)$ a Vickrey mechanism. For each $e \in \mathcal{E}$, if $f(e)=g(e)$, then $f$ is non-manipulable at $e$.

The following example shows that some Walrasian mechanism is manipulable at economies even if there are sufficiently many objects in the economies.

Example 1. Let $f=(x, t)$ be a minimum price Walrasian mechanism. Let $N \equiv\{i, j\}$ and $R \equiv\left(R_{i}, R_{j}\right)$ be such that for each $x_{i} \in X \backslash\{0\}$,

$$
v_{i}\left(x_{i}\right)=10 x_{i}+10, \text { and } v_{j}\left(x_{i}\right)=5 x_{i}+20
$$

Then, for each $e \equiv(N, R, \bar{x}) \in \mathcal{E}$ with $\bar{x} \geq 2$,

$$
p_{\min }(e)=10, x_{i}(e)=\bar{x}-1, \text { and } x_{j}(e)=1 .
$$

\footnotetext{
${ }^{10} \mathrm{Gul}$ and Stacchetti (1999) characterize the minimum and maximum Walrasian equilibrium prices by means of surplus function for more general setting where there can be heterogeneous objects. Although Proposition 1 is derived from their result, some calculation is required. Thus, we directly prove Proposition 1 instead of deriving it from the result by Gul and Stacchetti (1999).
} 
Let $R_{i}^{\prime} \in \mathcal{R}$ be such that for each $x_{i} \in X \backslash\{0\}$,

$$
v_{i}^{\prime}\left(x_{i}\right)=8 x_{i}+12
$$

For each $e^{\prime} \equiv\left(N,\left(R_{i}^{\prime}, R_{j}\right), \bar{x}\right) \in \mathcal{E}$ with $\bar{x} \geq 2$,

$$
p_{\min }\left(e^{\prime}\right)=8, x_{i}\left(e^{\prime}\right)=\bar{x}-1, \text { and } x_{j}\left(e^{\prime}\right)=1
$$

Therefore, for each $\bar{x} \in X$ with $\bar{x} \geq 2$, denoting $e \equiv(N, R, \bar{x})$ and $e^{\prime} \equiv\left(N,\left(R_{i}^{\prime}, R_{j}\right), \bar{x}\right)$,

$$
\begin{aligned}
& v_{i}\left(x_{i}(e)\right)-t_{i}(e)-\left(v_{i}\left(x_{i}\left(e^{\prime}\right)\right)-t_{i}\left(e^{\prime}\right)\right) \\
& \quad=v_{i}(\bar{x}-1)-10 \cdot(\bar{x}-1)-\left(v_{i}(\bar{x}-1)-8 \cdot(\bar{x}-1)\right) \\
& \quad=2(\bar{x}-1),
\end{aligned}
$$

which implies $f_{i}\left(e^{\prime}\right) P_{i} f_{i}(e)$, and hence $f$ is manipulable at $e$.

A feature of this example is that agent $i$ has higher incremental valuations at sufficiently large numbers of objects than agent $j$. That is, for each $x_{i} \in X$ with $x_{i}>1$, we have $v_{i}\left(x_{i}+1\right)-v_{i}\left(x_{i}\right)>v_{j}\left(x_{i}+1\right)-v_{j}\left(x_{i}\right)$. The following definition formalizes this feature.

Definition 4. Given $N \in \mathcal{N}, R \in \mathcal{R}^{|N|}$, and a pair $i, j \in N$, agent $i$ asymptotically dominates agent $j$ at $(N, R)$ if there is $\hat{x} \in X$ such that for each $x_{i} \in X$ with $x_{i} \geq \hat{x}, v_{i}\left(x_{i}+1\right)-v_{i}\left(x_{i}\right)>$ $v_{j}\left(x_{i}+1\right)-v_{j}\left(x_{i}\right)$.

As we have seen in Example 1, if there is an agent asymptotically dominating any other agents, there is a Walrasian mechanism that is manipulable at economies with many objects. We consider economies where there does not exist an agent asymptotically dominating any other agents.

Definition 5. Given $N \in \mathcal{N}$ and $R \in \mathcal{R}^{|N|},(N, R)$ satisfies no asymptotic domination if there is no agent $i \in N$ who asymptotically dominates agent $j$ at $(N, R)$ for each $j \in N \backslash\{i\}$.

The following result states that for each Walrasian mechanism, there is a Vickrey mechanism that coincides with the Walrasian mechanism at economies where no asymptotically domination is satisfied and there are sufficiently many objects. 
Theorem 1. Let $f=(x, t)$ be a Walrasian mechanism and $g=(x, s)$ a Vickrey mechanism. Let $N \in \mathcal{N}$ and $R \in \mathcal{R}^{|N|}$. Suppose $(N, R)$ satisfies no asymptotic domination. There is $\hat{x} \in X$ such that for each $e:=(N, R, \bar{x}) \in \mathcal{E}$ with $\bar{x} \geq \hat{x}, f(e)=g(e)$.

By Proposition 2, we have the following corollary.

Corollary 1. Let $f=(x, t)$ be a Walrasian mechanism. Let $N \in \mathcal{N}$ and $R \in \mathcal{R}^{|N|}$. Suppose $(N, R)$ satisfies no asymptotic domination. There is $\hat{x} \in X$ such that for each $e:=(N, R, \bar{x}) \in \mathcal{E}$ with $\bar{x} \geq \hat{x}, f$ is non-manipulable at $e$.

\section{Replica economies}

In the previous section, we focus only on cases where there are sufficiently many objects and there may not be many agents. In this section, we focus on cases where there are sufficiently many objects and agents. Precisely, we consider replica economies and investigate the incentive properties of Walrasian mechanisms.

Given $e:=(N, R, \bar{x}) \in \mathcal{E}$ and $R_{0} \in \mathcal{R}$, let $N\left(R_{0} ; e\right):=\left\{i \in N: R_{i}=R_{0}\right\}$.

Definition 6. Given $e:=(N, R, \bar{x}) \in \mathcal{E}$ and $K \in \mathbb{N}$, an economy $e^{\prime}:=\left(N^{\prime}, R^{\prime}, \bar{x}^{\prime}\right) \in \mathcal{E}$ is the $K$-replica of $e$ if (i) $\left|N\left(R_{i} ; e^{\prime}\right)\right|=K \cdot\left|N\left(R_{i} ; e\right)\right|$ for each $i \in N^{\prime}$ and (ii) $\bar{x}^{\prime}=K \cdot \bar{x}$.

Note that condition (i) implies $\left|N^{\prime}\right|=K \cdot|N|$.

The following theorem states that if an economy is replicated sufficiently many times, then for each minimum price Walrasian mechanism, there is a Vickrey mechanism that coincides with the minimum price Walrasian mechanism at the replica economy.

Theorem 2. Let $f:=(x, t)$ be a minimum price Walrasian mechanism and $g:=(x, s) a$ Vickrey mechanism. Let $e:=(N, R, \bar{x}) \in \mathcal{E}$ and $K \in \mathbb{N}$ be such that $K>\max _{i \in N} x_{i}(e)$. Let $e^{\prime}:=\left(N^{\prime}, R^{\prime}, \bar{x}^{\prime}\right) \in \mathcal{E}$ be the $K$-replica economy of $e$. Then, $f\left(e^{\prime}\right)=g\left(e^{\prime}\right)$

Remark 3. Gul and Stacchetti (1999) also show that in the model with possibly several different types of objects, if an economy is replicated sufficiently many times, each minimum price Walrasian mechanism coincides with a Vickrey mechanism at the replica economy. However, they assume that each agent can receive at most one object for each type. Since we do not make this assumption, the result by Gul and Stacchetti (1999) does 
not imply Theorem 2 .

By Proposition 2, we have the following corollary.

Corollary 2. Let $f$ be a minimum price Walrasian mechanism. Let $e:=(N, R, \bar{x}) \in \mathcal{E}$ and $K \in \mathbb{N}$ be such that $K>\max _{i \in N} x_{i}(e)$. Let $e^{\prime}:=\left(N^{\prime}, R^{\prime}, \bar{x}^{\prime}\right) \in \mathcal{E}$ be the $K$-replica economy of $e$. Then, $f$ is non-manipulable at $e^{\prime}$.

One may argue that Theorem 2 and Corollary 2 hold for any Walrasian mechanism. The following example shows that there is a Walrasian mechanism such that at any replica of an economy, the Walrasian mechanism is manipulable and does not coincide with any Vickrey mechanism.

Example 2. Let $f:=(x, t)$ be a maximal price Walrasian mechanism, and $g:=(y, s)$ a Vickrey mechanism. Let $e:=(N, R, \bar{x}) \in \mathcal{E}$ be such that $N=\{i, j\}, \bar{x}=2$, and for each $x_{i} \in X$,

$$
v_{i}\left(x_{i}\right)=\left\{\begin{array}{ll}
x_{i} & \text { if } x_{i} \leq 2, \\
2 & \text { otherwise },
\end{array} \text { and } v_{j}\left(x_{i}\right)= \begin{cases}2 x_{i} & \text { if } x_{i} \leq 2 \\
4 & \text { otherwise }\end{cases}\right.
$$

Let $K \in \mathbb{N}$ and $e^{\prime}:=\left(N^{\prime}, R^{\prime}, \bar{x}^{\prime}\right)$ be the $K$-replica of $e$. For each $k \in N^{\prime}$,

$$
x_{k}\left(e^{\prime}\right)=y_{k}\left(e^{\prime}\right)= \begin{cases}0 & \text { if } R_{k}^{\prime}=R_{i}, \\ 2 & \text { otherwise }\end{cases}
$$

By (ii) of Proposition $1, p_{\max }\left(e^{\prime}\right)=2$. Thus, for each $k \in N^{\prime}$ with $R_{k}=R_{j}, t_{k}\left(e^{\prime}\right)=4$. It is also easy to see that for each $k \in N^{\prime}$ with $R_{k}=R_{j}, s_{k}\left(e^{\prime}\right)=2$. Hence, $f\left(e^{\prime}\right) \neq g\left(e^{\prime}\right)$.

Moreover, $f$ is manipulable at $e^{\prime}$. To see this, let $k \in N^{\prime}$ be such that $R_{k}^{\prime}=R_{j}$ and let $R_{k}^{\prime \prime} \in \mathcal{R}$ be such that for each $x_{k} \in X$,

$$
v_{k}^{\prime \prime}\left(x_{k}\right)= \begin{cases}1.5 x_{k} & \text { if } x_{k} \leq 2 \\ 3 & \text { otherwise }\end{cases}
$$


Denote $e^{\prime \prime}=\left(N^{\prime},\left(R_{k}^{\prime \prime}, R_{-k}^{\prime}\right), \bar{x}^{\prime}\right)$. Then, for each $\ell \in N^{\prime}$,

$$
x_{\ell}\left(e^{\prime \prime}\right)= \begin{cases}0 & \text { if } R_{\ell}^{\prime}=R_{i}, \\ 2 & \text { otherwise }\end{cases}
$$

Moreover, by (ii) of Proposition $1, p_{\max }\left(e^{\prime \prime}\right)=1.5$. Thus, $f_{k}\left(e^{\prime \prime}\right)=(2,3) P_{k}^{\prime}(2,4)=f_{k}\left(e^{\prime}\right)$.

\section{Appendix}

\section{A Proofs of Propositions}

\section{A.1 Proof of (i) of Proposition 1}

Let $p:=\max \left\{v_{i}\left(x_{i}+1\right)-v_{i}\left(x_{i}\right): i \in N, x_{i} \neq \bar{x}\right\}$.

Claim 1: Let $i \in N$ be such that $x_{i}>0$. Then, $v_{i}\left(x_{i}\right)-v_{i}\left(x_{i}-1\right) \geq p$.

Proof. Let $j \in N$ be such that $x_{j} \neq \bar{x}$ and $v_{j}\left(x_{j}+1\right)-v_{j}\left(x_{j}\right)=p$. If $i=j$, then submodularity implies $v_{i}\left(x_{i}\right)-v_{i}\left(x_{i}-1\right)=v_{j}\left(x_{j}\right)-v_{j}\left(x_{j}-1\right) \geq v_{j}\left(x_{j}+1\right)-v_{j}\left(x_{j}\right)=p$ If $i \neq j$, then Remark 2 implies $v_{i}\left(x_{i}\right)-v_{i}\left(x_{i}-1\right) \geq v_{j}\left(x_{j}+1\right)-v_{j}\left(x_{j}\right)=p$.

Claim 2: $p \in P^{W}(e)$.

Proof. We show $\left(\left(x_{i}, p \cdot x_{i}\right)\right)_{i \in N} \in Z^{W}(e)$. To show this, we show that for each $i \in N$, $x_{i} \in D\left(R_{i}, p, \bar{x}\right)$. Let $i \in N$ and $y_{i} \in X$ be such that $y_{i} \neq x_{i}$.

Case 1: $y_{i}<x_{i}$. By Claim 1 and submodularity,

$$
\begin{aligned}
p \cdot\left(x_{i}-y_{i}\right) & \leq\left(v_{i}\left(x_{i}\right)-v_{i}\left(x_{i}-1\right)\right) \cdot\left(x_{i}-y_{i}\right) \\
& \leq\left(v_{i}\left(x_{i}\right)-v_{i}\left(x_{i}-1\right)\right)+\left(v_{i}\left(x_{i}-1\right)-v_{i}\left(x_{i}-2\right)\right)+\cdots+\left(v_{i}\left(y_{i}+1\right)-v_{i}\left(y_{i}\right)\right) \\
& =v_{i}\left(x_{i}\right)-v_{i}\left(y_{i}\right)
\end{aligned}
$$


Thus,

$$
\begin{aligned}
v_{i}\left(x_{i}\right)-p \cdot x_{i} & =v_{i}\left(x_{i}\right)-p \cdot\left(x_{i}-y_{i}\right)-p \cdot y_{i} \\
& \geq v_{i}\left(x_{i}\right)-\left(v_{i}\left(x_{i}\right)-v_{i}\left(y_{i}\right)\right)-p \cdot y_{i} \\
& v_{i}\left(y_{i}\right)-p \cdot y_{i} .
\end{aligned}
$$

Hence, $\left(x_{i}, p \cdot x_{i}\right) R_{i}\left(y_{i}, p \cdot y_{i}\right)$.

Case 2: $y_{i}>x_{i}$. By the definition of $p$ and submodularity,

$$
\begin{aligned}
p \cdot\left(y_{i}-x_{i}\right) & \geq\left(v_{i}\left(x_{i}+1\right)-v_{i}\left(x_{i}\right)\right) \cdot\left(y_{i}-x_{i}\right) \\
& \geq\left(x_{i}\left(x_{i}+1\right)-v_{i}\left(x_{i}\right)\right)+\left(v_{i}\left(x_{i}+2\right)-v_{i}\left(x_{i}-1\right)\right)+\cdots+\left(v_{i}\left(y_{i}\right)-v_{i}\left(y_{i}-1\right)\right) \\
& =v_{i}\left(y_{i}\right)-v_{i}\left(x_{i}\right) .
\end{aligned}
$$

Thus,

$$
\begin{aligned}
v_{i}\left(x_{i}\right)-p \cdot x_{i} & =v_{i}\left(x_{i}\right)+p \cdot\left(y_{i}-x_{i}\right)-p \cdot y_{i} \\
& \geq v_{i}\left(x_{i}\right)+v_{i}\left(y_{i}\right)-v_{i}\left(x_{i}\right)-p \cdot y_{i} \\
& =v_{i}\left(y_{i}\right)-p \cdot y_{i} .
\end{aligned}
$$

Hence, $\left(x_{i}, p \cdot x_{i}\right) R_{i}\left(y_{i}, p \cdot y_{i}\right)$.

Suppose by contradiction that there is $p^{\prime} \in P^{W}(e)$ such that $p^{\prime}<p$. By $p^{\prime} \in P^{W}(e), x \in$ $P(e)$, and Fact 3, we have $\left(\left(x_{i}, p^{\prime} \cdot x_{i}\right)\right)_{i \in N} \in Z^{W}(e)$. Thus, for each $i \in N, x_{i} \in D\left(R_{i}, p^{\prime}, \bar{x}\right)$.

Let $i \in N$ be such that $x_{i} \neq \bar{x}$ and $v_{i}\left(x_{i}+1\right)-v_{i}\left(x_{i}\right)=p$. Note that such an agent always exists. Then,

$$
\begin{aligned}
v_{i}\left(x_{i}+1\right)-p^{\prime} \cdot\left(x_{i}+1\right) & =v_{i}\left(x_{i}+1\right)-p^{\prime}-p^{\prime} \cdot x_{i} \\
& >v_{i}\left(x_{i}+1\right)-p-p^{\prime} \cdot x_{i} \\
& =v_{i}\left(x_{i}+1\right)-\left(v_{i}\left(x_{i}+1\right)-v_{i}\left(x_{i}\right)\right)-p^{\prime} \cdot x_{i} \\
& =v_{i}\left(x_{i}\right)-p^{\prime} \cdot x_{i} .
\end{aligned}
$$

This implies $x_{i} \notin D\left(R_{i}, p^{\prime}, \bar{x}\right)$, a contradiction. 


\section{A.2 Proof of (ii) of Proposition 1}

Let $p:=\min \left\{v_{i}\left(x_{i}\right)-v_{i}\left(x_{i}-1\right): i \in N, x_{i}>0\right\}$.

Claim 3: $p \in P^{W}(e)$.

Proof. We show $\left(\left(x_{i}, p \cdot x_{i}\right)\right)_{i \in N} \in Z^{W}(e)$. To show this, we show that for each $i \in N$, $x_{i} \in D\left(R_{i}, p, \bar{x}\right)$. Let $i \in N$ and $y_{i} \in X$ be such that $y_{i} \neq x_{i}$.

Case 1: $y_{i}<x_{i}$. By the definition of $p$ and submodularity,

$$
\begin{aligned}
p \cdot\left(x_{i}-y_{i}\right) & \leq\left(v_{i}\left(x_{i}\right)-v_{i}\left(x_{i}-1\right)\right) \cdot\left(x_{i}-y_{i}\right) \\
& \leq\left(v_{i}\left(x_{i}\right)-v_{i}\left(x_{i}-1\right)\right)+\left(v_{i}\left(x_{i}-1\right)-v_{i}\left(x_{i}-2\right)\right)+\cdots+\left(v_{i}\left(y_{i}+1\right)-v_{i}\left(y_{i}\right)\right) \\
& =v_{i}\left(x_{i}\right)-v_{i}\left(y_{i}\right)
\end{aligned}
$$

Thus,

$$
\begin{aligned}
v_{i}\left(x_{i}\right)-p \cdot x_{i} & =v_{i}\left(x_{i}\right)-p \cdot\left(x_{i}-y_{i}\right)-p \cdot y_{i} \\
& \geq v_{i}\left(x_{i}\right)-\left(v_{i}\left(x_{i}\right)-v_{i}\left(y_{i}\right)\right)-p \cdot y_{i} \\
& =v_{i}\left(y_{i}\right)-p \cdot y_{i} .
\end{aligned}
$$

Hence, $\left(x_{i}, p \cdot x_{i}\right) R_{i}\left(y_{i}, p \cdot y_{i}\right)$.

Case 2: $y_{i}>x_{i}$. Let $j \in N$ be such that $x_{j}>0$ and $v_{j}\left(x_{j}\right)-v_{j}\left(x_{j}-1\right)=p$. By Remark 2, $v_{i}\left(x_{i}+1\right)-v_{i}\left(x_{i}\right) \leq v_{j}\left(x_{j}\right)-v_{j}\left(x_{j}-1\right)=p$. Thus, by submodularity,

$$
\begin{aligned}
p \cdot\left(y_{i}-x_{i}\right) & \geq\left(v_{i}\left(x_{i}+1\right)-v_{i}\left(x_{i}\right)\right) \cdot\left(y_{i}-x_{i}\right) \\
& \geq\left(v_{i}\left(x_{i}+1\right)-v_{i}\left(x_{i}\right)\right)+\left(v_{i}\left(x_{i}+2\right)-v_{i}\left(x_{i}+1\right)\right)+\cdots+\left(v_{i}\left(y_{i}\right)-v_{i}\left(y_{i}-1\right)\right) \\
& =v_{i}\left(y_{i}\right)-v_{i}\left(x_{i}\right) .
\end{aligned}
$$


Thus,

$$
\begin{aligned}
v_{i}\left(x_{i}\right)-p \cdot x_{i} & =v_{i}\left(x_{i}\right)+p \cdot\left(y_{i}-x_{i}\right)-p \cdot y_{i} \\
& \geq v_{i}\left(x_{i}\right)+v_{i}\left(y_{i}\right)-v_{i}\left(x_{i}\right)-p \cdot y_{i} \\
& =v_{i}\left(y_{i}\right)-p \cdot y_{i} .
\end{aligned}
$$

Hence, $\left(x_{i}, p \cdot x_{i}\right) R_{i}\left(y_{i}, p \cdot y_{i}\right)$.

By contradiction, suppose that there is $p^{\prime} \in P^{W}(e)$ such that $p^{\prime}>p$. By $p^{\prime} \in P^{W}(e)$, $x \in P(e)$, and Fact 3, we have $\left(\left(x_{i}, p^{\prime} \cdot x_{i}\right)\right)_{i \in N} \in Z^{W}(e)$. Thus, for each $i \in N, x_{i} \in$ $D\left(R_{i}, p^{\prime}, \bar{x}\right)$.

Let $i \in N$ be such that $x_{i}>0$ and $v_{i}\left(x_{i}\right)-v_{i}\left(x_{i}-1\right)=p$. Note that such an agent always exists. Then,

$$
\begin{aligned}
v_{i}\left(x_{i}\right)-p \cdot x_{i} & =v_{i}\left(x_{i}\right)-p^{\prime}-p^{\prime} \cdot\left(x_{i}-1\right) \\
& <v_{i}\left(x_{i}\right)-p-p^{\prime} \cdot\left(x_{i}-1\right) \\
& =v_{i}\left(x_{i}\right)-\left(v_{i}\left(x_{i}\right)-v_{i}\left(x_{i}-1\right)\right)-p^{\prime} \cdot\left(x_{i}-1\right) \\
& =v_{i}\left(x_{i}-1\right)-p^{\prime} \cdot\left(x_{i}-1\right) .
\end{aligned}
$$

This implies $x_{i} \notin D\left(R_{i}, p^{\prime}, \bar{x}\right)$, a contradiction.

\section{A.3 Proof of Proposition 2}

Let $e \equiv(N, R, \bar{x}) \in \mathcal{E}, i \in N$ and $R_{i}^{\prime} \in \mathcal{R}$. Denote $e^{\prime} \equiv\left(N,\left(R_{i}^{\prime}, R_{-i}\right), \bar{x}\right)$. By $f_{i}(e)=g_{i}(e)$, strategy-proofness of $g$, and Fact 4, we have

$$
f_{i}(e)=g_{i}(e) R_{i} g_{i}\left(e^{\prime}\right) R_{i} f_{i}\left(e^{\prime}\right)
$$




\section{B Proof of Theorem 1}

First we introduce several notations. For each $i \in N$, by submodularity, $v_{i}(x+1)-v_{i}(x)$ is non-increasing in $x$, and by monotonicity, the sequence $\left\{v_{i}(x+1)-v_{i}(x)\right\}_{x \in \mathbb{N}}$ is bounded below. Therefore, the sequence $\left\{v_{i}(x+1)-v_{i}(x)\right\}_{x_{i} \in \mathbb{N}}$ has the limit, which is denoted by $v_{i}^{*}$. Note that by submodularity, for each $i \in N$ and $x_{i} \in X, v_{i}\left(x_{i}+1\right)-v_{i}\left(x_{i}\right) \geq v_{i}^{*}$. Moreover, by the assumption of integer values, for each $i \in N$, there is $x_{i}^{*} \in X$ such that for each $x_{i} \in X$,

$$
v_{i}\left(x_{i}+1\right)-v_{i}\left(x_{i}\right) \begin{cases}>v_{i}^{*} & \text { if } x_{i}<x_{i}^{*}, \\ =v_{i}^{*} & \text { if } x_{i} \geq x_{i}^{*}\end{cases}
$$

Let $N^{*}$ be the set of agents who are not asymptotically dominated by any agent. Denote $v^{*}:=\max _{j} v_{j}^{*}$.

Step 1. $N^{*}=\left\{i \in N: v_{i}^{*}=v^{*}\right\}$ and $\left|N^{*}\right| \geq 2$.

Proof. First we show the following claim.

Claim 4: Let $i \in N$ and $j \in N$. Agent $i$ asymptotically dominates agent $j$ if and only if $v_{i}^{*}>v_{j}^{*}$.

Proof. Let $x^{*}=\max \left\{x_{i}^{*}, x_{j}^{*}\right\}$. Then, for each $x \in X$ with $x \geq x^{*}$,

$$
v_{i}(x+1)-v_{i}(x)=v_{i}^{*} \text {, and } v_{j}(x+1)-v_{j}(x)=v_{j}^{*}
$$

Thus, $v_{i}(x+1)-v_{i}(x)>v_{j}(x+1)-v_{j}(x)$ for each $x \in X$ with $x \geq x^{*}$ if and only if $v_{i}^{*}>v_{j}^{*}$. Hence, agent $i$ asymptotically dominates agent $j$ if and only if $v_{i}^{*}>v_{j}^{*}$.

For each $i \in N^{*}$, agent $i$ is not asymptotically dominated by agent other agent. Thus, by Claim 3, for each $i \in N^{*}$ and each $j \in N \backslash\{i\}, v_{i}^{*} \geq v_{j}^{*}$, and thus, $v_{i}^{*}=v^{*}$. Hence, we have $N^{*} \subseteq\left\{i \in N: v_{i}^{*}=v^{*}\right\}$.

On the other hand, let $i \in N$ be such that $v_{i}^{*}=v^{*}$. By the definition of $v^{*}$, for each $j \in N \backslash\{i\}, v_{i}^{*} \geq v_{j}^{*}$. Thus, by Claim 3, agent $i$ is not asymptotically dominated by any other agent, which implies $i \in N^{*}$. Hence, we conclude that $N^{*}=\left\{i \in N: v_{i}^{*}=v^{*}\right\}$. 
Since $N$ is finite, there is $i \in N$ such that $v_{i}^{*}=\max _{j \in N} v_{j}^{*}$. Thus, $i \in N^{*}$ and $\left|N^{*}\right| \geq 1$. If $\left|N^{*}\right|=1$, then for each $j \in N \backslash\{i\}, v_{i}^{*}>v_{j}^{*}$, and by Claim 3, agent $i$ asymptotically dominates agent $j$. This contradicts no asymptotic domination. Hence, $\left|N^{*}\right| \geq 2$.

Let $\hat{x}^{*} \in X$ be such that $\hat{x}^{*}>\sum_{i \in N} x_{i}^{*}$.

Step 2. Let e $:=(N, R, \bar{x}) \in \mathcal{E}$ be such that $\bar{x} \geq \hat{x}^{*}$. Then, the followings are satisfied:

(i) For each $i \in N \backslash N^{*}, x_{i}(e) \leq x_{i}^{*}$.

(ii) For each $i \in N^{*}, x_{i}(e) \geq x_{i}^{*}$.

Proof. (i) By contradiction, suppose that there is $i \in N \backslash N^{*}$ such that $x_{i}(e)>x_{i}^{*}$.

By $x_{i}(e)>x_{i}^{*}$ and $i \notin N^{*}, v_{i}\left(x_{i}(e)\right)-v_{i}\left(x_{i}(e)-1\right)=v_{i}^{*}<v^{*}$. Take any $j \in N^{*}$. Then, $v_{j}\left(x_{j}(e)+1\right)-v_{j}\left(x_{j}(e)\right) \geq v^{*}$. Thus,

$$
v_{i}\left(x_{i}(e)\right)-v_{i}\left(x_{i}(e)-1\right)<v^{*} \leq v_{j}\left(x_{j}(e)+1\right)-v_{j}\left(x_{j}(e)\right) .
$$

This contradicts Remark 2.

(ii) By contradiction, suppose that there is $i \in N^{*}$ such that $x_{i}(e)<x_{i}^{*}$. By the definition of $x_{i}^{*}, v_{i}\left(x_{i}(e)+1\right)-v_{i}\left(x_{i}(e)\right)>v^{*}$. We have two cases.

Case 1: $\sum_{j \in N} x_{j}(e)<\bar{x}$. Let $y:=\left(y_{j}\right)_{j \in N}$ be such that

$$
y_{i}=x_{i}(e)+1 \text { and for each } j \in N \backslash\{i\}, y_{j}=x_{j}(e) \text {. }
$$

Note that $\sum_{j \in N} y_{j}=1+\sum_{j \in N} x_{j}(e) \leq \bar{x}$. Thus, $y \in A(e)$. By $v_{i}\left(x_{i}(e)+1\right)-v_{i}\left(x_{i}(e)\right)>v^{*} \geq 0$, $v_{i}\left(x_{i}(e)+1\right)>v_{i}\left(x_{i}(e)\right)$. Thus,

$$
\sum_{j \in N} v_{j}\left(y_{j}\right)=v_{i}\left(x_{i}(e)+1\right)+\sum_{j \in N \backslash\{i\}} v_{j}\left(x_{j}(e)\right)>\sum_{j \in N} v_{j}\left(x_{j}(e)\right)
$$

which contradicts $x(e) \in P(e)$.

Case 2: $\sum_{j \in N} x_{j}(e)=\bar{x}$. By $\bar{x} \geq \hat{x}^{*}>\sum_{j \in N} x_{j}^{*}$, there is $j \in N$ such that $x_{j}(e)>x_{j}^{*}$. By $x_{i}(e)<x_{i}^{*}$, we have $j \neq i$, and by (i) of Step 2, $j \in N^{*}$. By $x_{j}(e)>x_{j}^{*}$ and $j \in N^{*}$, 
$v_{j}\left(x_{j}(e)\right)-v_{j}\left(x_{j}(e)-1\right)=v^{*}$. Therefore,

$$
v_{j}\left(x_{j}(e)\right)-v_{j}\left(x_{j}(e)-1\right)=v^{*}<v_{i}\left(x_{i}(e)+1\right)-v_{i}\left(x_{i}(e)\right) .
$$

This contradicts Remark 2.

Step 3. Let $e:=(N, R, \bar{x}) \in \mathcal{E}$ be such that $\bar{x} \geq \hat{x}^{*}$. Then, $p_{\min }(e)=p_{\max }(e)=v^{*}$.

Proof. We have two cases.

Case 1: $\sum_{i \in N} x_{i}(e)<\bar{x}$. By WE-ii, we have $p_{\max }(e)=p_{\min }(e)=0$. By Remark $1, v^{*}=0$. Hence, $p_{\max }(e)=p_{\min }(e)=v^{*}$.

Case 2: $\sum_{i \in N} x_{i}(e)=\bar{x}$. By Step $1,\left|N^{*}\right| \geq 2$. Thus, $\left\{i \in N^{*}: x_{i}(e)<\bar{x}\right\} \neq \emptyset$. Take any $i \in\left\{i \in N^{*}: x_{i}(e)<\bar{x}\right\}$. Then, by $i \in N^{*}, v_{i}\left(x_{i}(e)+1\right)-v_{i}\left(x_{i}(e)\right) \geq v^{*}$. Thus, by (i) of Proposition 1

$$
p_{\min }(e) \geq v_{i}\left(x_{i}(e)+1\right)-v_{i}\left(x_{i}(e)\right) \geq v^{*} .
$$

By $\bar{x}>\sum_{i \in N} x_{i}^{*}$ and $\sum_{j \in N} x_{j}(e)=\bar{x}$, there is $j \in N^{*}$ such that $x_{j}(e)>x_{j}^{*}$. By (i) of Step $2, j \in N^{*}$. Thus, by the definition of $x_{j}^{*}, v_{j}\left(x_{j}(e)\right)-v_{j}\left(x_{j}(e)-1\right)=v^{*}$. Therefore, by (ii) of Proposition 1,

$$
p_{\max }(e) \leq v_{j}\left(x_{j}(e)\right)-v_{j}\left(x_{j}(e)-1\right)=v^{*} .
$$

Hence, $v^{*} \leq p_{\min }(e) \leq p_{\max }(e) \leq v^{*}$, implying $p_{\min }(e)=p_{\max }(e)=v^{*}$.

Given $e:=(N, R, \bar{x}) \in \mathcal{E}$ and $i \in N$, let $e_{-i}:=\left(N_{-i}, R_{-i}, \bar{x}-x_{i}(e)\right)$.

Step 4. Let $e:=(N, R, \bar{x}) \in \mathcal{E}$ and $i \in N$. There is $y \in P\left(e_{-i}\right)$ such that for each $j \in N_{-i}$, $y_{j} \geq x_{j}(e)$.

Proof. Suppose by contradiction that for each $y \in P\left(e_{-i}\right), y_{j}<x_{j}(e)$ for some $j \in N_{-i}$. Let

$$
P^{*}:=\underset{y \in P\left(e_{-i}\right)}{\arg \min }\left|\left\{j \in N_{-i}: y_{j}<x_{j}(e)\right\}\right|
$$

Let $j \in N_{-i}$ be such that $y_{j}<x_{j}(e)$ for some $y \in P^{*}$, and let $P^{*}(j):=\left\{y \in P^{*}: y_{j}<x_{j}(e)\right\}$. 
Let

$$
y^{*} \in \underset{y \in P^{*}(j)}{\arg \max } y_{j}
$$

Claim 5: There is $k \in N \backslash\{i, j\}$ such that $y_{k}^{*}>x_{k}(e)$.

Proof. Suppose by contradiction that for each $k \in N \backslash\{i, j\} y_{k}^{*} \leq x_{k}(e)$. Then, by $y_{j}<x_{j}(e)$, $\sum_{k \in N_{-i}} y_{k}^{*}<\sum_{k \in N_{-i}} x_{k}(e)$. Let $y:=\left(y_{k}\right)_{k \in N_{-i}}$ be such that $y_{j}=y_{j}^{*}+1$ and for each $k \in N_{-i} \backslash\{j\}$, $y_{j}=y_{k}^{*}$. Note that $\sum_{k \in N_{-i}} y_{k}=1+\sum_{k \in N_{-i}} y_{k}^{*} \leq \sum_{k \in N_{-i}} x_{k}(e) \leq \bar{x}-x_{i}(e)$. Thus, $y \in A\left(e_{-i}\right)$. Moreover, by $v_{j}\left(y_{j}\right)=v_{j}\left(y_{j}^{*}+1\right) \geq v_{j}\left(y_{j}^{*}\right), \sum_{k \in N_{-i}} v_{k}\left(y_{k}\right) \geq \sum_{k \in N_{-i}} v_{k}\left(y_{k}^{*}\right)$. Thus, $y^{*} \in P\left(e_{-i}\right)$ implies $y \in P\left(e_{-i}\right)$.

If $y_{j}=x_{j}(e)$, then

$$
\left|\left\{k \in N_{-i}: y_{k}<x_{k}(e)\right\}\right|<\left|\left\{k \in N_{-i}: y_{k}^{*}<x_{k}(e)\right\}\right|,
$$

which contradicts $y^{*} \in P^{*}$. Thus, $y_{j}<x_{j}(e)$. By $y_{j}>y_{j}^{*}$, however, this also contradicts $y^{*} \in P^{*}(j)$.

Claim 6: $v_{j}\left(y_{j}^{*}+1\right)-v_{j}\left(y_{j}^{*}\right)<v_{k}\left(y_{k}^{*}\right)-v_{k}\left(y_{k}^{*}-1\right)$.

Proof. Suppose by contradiction that $v_{j}\left(y_{j}^{*}+1\right)-v_{j}\left(y_{j}^{*}\right) \geq v_{k}\left(y_{k}^{*}\right)-v_{k}\left(y_{k}^{*}-1\right)$. Let $y \in A\left(e_{-i}\right)$ be such that $y_{j}=y_{j}^{*}+1, y_{k}=y_{k}^{*}-1$, and for each $\ell \in N \backslash\{i, j, k\}, y_{\ell}=y_{\ell}^{*}$. Then,

$$
\sum_{\ell \in N_{-i}} v_{\ell}\left(y_{\ell}\right)=v_{j}\left(y_{j}^{*}+1\right)+v_{k}\left(y_{k}^{*}-1\right)+\sum_{\ell \in N \backslash\{i, j, k\}} v_{\ell}\left(y_{\ell}^{*}\right) \geq \sum_{\ell \in N_{-i}} v_{\ell}\left(y_{\ell}^{*}\right)
$$

By $y^{*} \in P\left(e_{-i}\right)$, we have $y \in P\left(e_{-i}\right)$.

If $y_{j}=x_{j}(e)$, then

$$
\left|\left\{\ell \in N_{-i}: y_{\ell}<x_{\ell}(e)\right\}\right|<\left|\left\{\ell \in N_{-i}: y_{\ell}^{*}<x_{\ell}(e)\right\}\right|,
$$

which contradicts $y^{*} \in P^{*}$. Thus, $y_{j}<x_{j}(e)$. By $y_{j}>y_{j}^{*}$, however, this also contradicts $y^{*} \in P^{*}(j)$. 
By $y_{j}^{*}<x_{j}(e)$, submodularity, and Claim 6,

$$
\begin{aligned}
v_{j}\left(x_{j}(e)\right)-v_{j}\left(x_{j}(e)-1\right) & \leq v_{j}\left(y_{j}^{*}+1\right)-v_{j}\left(y_{j}^{*}\right) \\
& <v_{k}\left(y_{k}^{*}\right)-v_{k}\left(y_{k}^{*}-1\right) \\
& \leq v_{k}\left(x_{k}(e)+1\right)-v_{k}\left(x_{k}(e)\right) .
\end{aligned}
$$

This contradicts Remark 2.

Given $e:=(N, R, \bar{x}) \in \mathcal{E}$ and $i \in N$, let

$$
\begin{aligned}
P^{*}\left(e_{-i}\right) & :=\left\{y \in P\left(e_{-i}\right): \text { for each } j \in N_{-i}, y_{j} \geq x_{j}(e)\right\}, \text { and } \\
P^{* *}\left(e_{-i}\right) & :=\left\{y \in P^{*}\left(e_{-i}\right): \text { for each } j \in N_{-i} \backslash N^{*}, y_{j}=x_{j}(e)\right\} .
\end{aligned}
$$

Step 5. Let $e:=(N, R, \bar{x}) \in \mathcal{E}$ be such that $\bar{x} \geq \hat{x}^{*}$, and $i \in N$. Then, $P^{* *}\left(e_{-i}\right) \neq \emptyset$.

Proof. By contradiction, suppose that $P^{* *}\left(e_{-i}\right)=\emptyset$. Then, for each $y \in P^{*}\left(e_{-i}\right)$, there is $j \in N_{-i} \backslash N^{*}$ such that $y_{j}>x_{j}(e)$. Let

$$
P^{*}:=\underset{y \in P^{*}\left(e_{-i}\right)}{\arg \max }\left|\left\{j \in N_{-i} \backslash N^{*}: y_{j}>x_{j}(e)\right\}\right| .
$$

Let $j \in N_{-i} \backslash N^{*}$ be such that $y_{j}>x_{j}(e)$ for some $y \in P^{*}$, and let $P^{*}(j):=\left\{y \in P^{*}: y_{j}>\right.$ $\left.x_{j}(e)\right\}$. Let

$$
y^{*} \in \underset{y \in P^{*}(j)}{\arg \min } y_{j}
$$

Claim 7: Let $k \in N^{*} \backslash\{i\}$. Then, $v_{k}\left(y_{k}^{*}+1\right)-v_{k}\left(y_{k}^{*}\right)<v_{j}\left(y_{j}^{*}\right)-v_{j}\left(y_{j}^{*}-1\right)$.

Proof. Suppose by contradiction that $v_{k}\left(y_{k}^{*}+1\right)-v_{k}\left(y_{k}^{*}\right) \geq v_{j}\left(y_{j}^{*}\right)-v_{j}\left(y_{j}^{*}-1\right)$. Let $y \in A\left(e_{-i}\right)$ be such that $y_{j}=y_{j}^{*}-1, y_{k}=y_{k}^{*}+1$, and for each $\ell \in N \backslash\{i, j, k\}, y_{\ell}=y_{\ell}^{*}$. Then, we have

$$
\sum_{\ell \in N \backslash\{i\}} v_{\ell}\left(y_{\ell}\right)=v_{j}\left(y_{j}^{*}-1\right)+v_{k}\left(y_{k}^{*}+1\right)+\sum_{\ell \in N \backslash\{i, j, k\}} v_{\ell}\left(y_{\ell}^{*}\right) \geq \sum_{\ell \in N \backslash\{i\}} v_{\ell}\left(y_{\ell}^{*}\right) .
$$

Thus, by $y^{*} \in P\left(e_{-i}\right)$, we have $y \in P\left(e_{-i}\right)$. 
If $y_{j}^{*}=x_{j}(e)$, then

$$
\left|\left\{j \in N_{-i} \backslash N^{*}: y_{j}>x_{j}(e)\right\}\right|<\left|\left\{j \in N_{-i} \backslash N^{*}: y_{j}^{*}>x_{j}(e)\right\}\right|,
$$

which contradicts $y^{*} \in P^{*}$. Thus, $y_{j}>x_{j}(e)$. By $y_{j}<y_{j}^{*}$, however, this also contradicts $y^{*} \in P^{*}(j)$.

Claim 8: $v_{j}\left(x_{j}(e)+1\right)-v_{j}\left(x_{j}(e)\right) \leq v^{*}$.

Proof. If $\sum_{k \in N} x_{k}(e)<\bar{x}$, then Remark 1 implies $v^{*}=0$ and thus $N^{*}=N$. Hence, since agent $j$ is chosen from $N_{-i} \backslash N^{*}$, we may assume $\sum_{k \in N} x_{k}(e)=\bar{x}$ without loss of generality.

By $\bar{x} \geq \hat{x}^{*}>\sum_{k \in N} x_{k}^{*}$ and $\sum_{k \in N} x_{k}(e)=\bar{x}$, there is $k \in N$ such that $x_{k}(e)>x_{k}^{*}$. By Step $2, k \in N^{*}$. By the definition of $x_{k}^{*}, v_{k}\left(x_{k}(e)\right)-v_{k}\left(x_{k}(e)-1\right)=v^{*}$. Thus, by Remark 2 ,

$$
v_{j}\left(x_{j}(e)+1\right)-v_{j}\left(x_{j}(e)\right) \leq v_{k}\left(x_{k}(e)\right)-v_{k}\left(x_{k}(e)-1\right)=v^{*} .
$$

By Step $1, N^{*} \backslash\{i\} \neq \emptyset$. Take any $k \in N^{*} \backslash\{i\}$. Then, $v_{k}\left(y_{k}^{*}+1\right)-v_{k}\left(y_{k}^{*}\right) \geq v^{*}$. Thus, by Claim $7, y_{j}^{*}>x_{j}(e)$, submodularity, and Claim 8 ,

$$
\begin{aligned}
v^{*} & \leq v_{k}\left(y_{k}^{*}+1\right)-v_{k}\left(y_{k}^{*}\right) \\
& <v_{j}\left(y_{j}^{*}\right)-v_{j}\left(y_{j}^{*}-1\right) \\
& \leq v_{j}\left(x_{j}(e)+1\right)-v_{j}\left(x_{j}(e)\right) \\
& \leq v^{*}
\end{aligned}
$$

This is a contradiction.

Step 6. Completing the proof.

Let $e:=(N, R, \bar{x}) \in \mathcal{E}$ be such that $\bar{x} \geq \hat{x}^{*}$, and let $i \in N$. Since $f$ is a Walrasian mechanism, there is $p \in P^{W}(e)$ such that $t_{i}(e)=p \cdot x_{i}(e)$. By Step $3, v^{*}=p_{\text {min }}(e) \leq p \leq$ $p_{\max }(e)=v^{*}$. Hence, $t_{i}(e)=x_{i}(e) \cdot v^{*}$.

By Step 5, $P^{* *}\left(e_{-i}\right) \neq \emptyset$. Let $y \in P^{* *}\left(e_{-i}\right)$. By (ii) of Step 2, for each $j \in N^{*} \backslash\{i\}$, 
$x_{j}(e) \geq x_{j}^{*}$. Thus, for each $j \in N^{*} \backslash\{i\}$ with $y_{j}>x_{j}(e)$,

$$
v_{j}\left(y_{j}\right)-v_{j}\left(y_{j}-1\right)=v_{j}\left(y_{j}-1\right)-v_{k}\left(y_{j}-2\right)=\cdots=v_{j}\left(x_{j}(e)+1\right)-v_{j}\left(x_{j}(e)\right)=v^{*} .
$$

By $y \in P^{* *}\left(e_{-i}\right)$, for each $j \in N^{*} \backslash\{i\}, y_{j} \geq x_{j}(e)$, and for each $j \in N_{-i} \backslash N^{*}, y_{j}=x_{j}(e)$. Therefore,

$$
\begin{aligned}
s_{i}(e) & =\sum_{j \in N_{-i}} v_{j}\left(y_{j}\right)-\sum_{j \in N_{-i}} v_{j}\left(x_{j}(e)\right) \\
& =\sum_{j \in N^{*} \backslash\{i\}}\left(v_{j}\left(y_{j}\right)-v_{j}\left(x_{j}(e)\right)\right) \\
& =\sum_{j \in N^{*} \backslash\{i\}}\left(v_{j}\left(y_{j}\right)-v_{j}\left(y_{j}-1\right)+v_{j}\left(y_{j}-1\right)-v_{k}\left(y_{j}-2\right)+\cdots+v_{j}\left(x_{j}(e)+1\right)-v_{j}\left(x_{j}(e)\right)\right) \\
& =\sum_{j \in N^{*} \backslash\{i\}}\left(y_{j}-x_{j}(e)\right) \cdot v^{*}
\end{aligned}
$$

If $v^{*}=0$, then $t_{i}(e)=0=s_{i}(e)$. If $v^{*}>0$, then Remark 1 implies $\sum_{j \in N} x_{j}(e)=$ $\sum_{j \in N_{-i}} y_{j}=\bar{x}$, and thus,

$$
\begin{aligned}
\sum_{j \in N^{*} \backslash\{i\}}\left(y_{j}-x_{j}(e)\right) & =\sum_{j \in N^{*} \backslash\{i\}}\left(y_{j}-x_{j}(e)\right)+\sum_{j \in N_{-i} \backslash N^{*}}\left(y_{j}-x_{j}(e)\right) \\
& =\bar{x}-\sum_{j \in N_{-i}} x_{j}(e) \\
& =x_{i}(e) .
\end{aligned}
$$

Hence, for the case of $v^{*}>0$,

$$
s_{i}(e)=\sum_{j \in N^{*} \backslash\{i\}}\left(y_{j}-x_{j}(e)\right) \cdot v^{*}=x_{i}(e) \cdot v^{*}=t_{i}(e) .
$$

\section{Proof of Theorem 2}

First, consider the case in which there is $x \in P\left(e^{\prime}\right)$ such that $\sum_{i \in N} x_{i}<\bar{x}^{\prime}$. By Fact 3, $\left(\left(x_{i}, p_{\min }\left(e^{\prime}\right) \cdot x_{i}\right)\right)_{i \in N^{\prime}} \in Z^{W}\left(e^{\prime}\right)$. Then, WE-ii implies $p_{\min }\left(e^{\prime}\right)=0$, and thus, for each 
$i \in N^{\prime}, t_{i}\left(e^{\prime}\right)=0$. Note also that for each $i \in N^{\prime}, s_{i}\left(e^{\prime}\right) \geq 0$ and By Fact $4, t_{i}\left(e^{\prime}\right) \geq s_{i}\left(e^{\prime}\right)$. Therefore, for each $i \in N^{\prime}, t_{i}\left(e^{\prime}\right)=s_{i}\left(e^{\prime}\right)$.

Hereafter we consider the case in which for each $x \in P\left(e^{\prime}\right), \sum_{i \in N^{\prime}} x_{i}=\bar{x}^{\prime}$. Since $e^{\prime}$ is the $K$-replica economy of $e$, there is $\left(N_{i}\right)_{i \in N}$ such that (i) $\bigcup_{i \in N} N_{i}=N^{\prime}$, (ii) for each pair $i, j \in N, N_{i} \cap N_{j}=\emptyset$, (iii) for each $i \in N,\left|N_{i}\right|=K$, and (iv) for each $i \in N$ and each $j \in N_{i}$, $R_{i}=R_{j}^{\prime}$. Let $x \in A\left(e^{\prime}\right)$ be such that for each $i \in N$ and each $j \in N_{i}, x_{j}=x_{i}(e)$.

Step 1. $x \in P\left(e^{\prime}\right)$.

Proof. Suppose by contradiction that $x \notin P\left(e^{\prime}\right)$. Let

$$
y^{*} \in \underset{y \in P\left(e^{\prime}\right)}{\arg \min } \sum_{i \in N^{\prime}}\left|y_{i}-x_{i}\right| .
$$

By $x \notin P\left(e^{\prime}\right)$ and $y^{*} \in P(e), \sum_{i \in N^{\prime}} v_{i}^{\prime}\left(y_{i}^{*}\right)>\sum_{i \in N^{\prime}} v_{i}^{\prime}\left(x_{i}\right)$. Thus, there is $i \in N^{\prime}$ such that $v_{i}^{\prime}\left(y_{i}^{*}\right)>v_{i}^{\prime}\left(x_{i}\right)$. By monotonicity, $y_{i}^{*}>x_{i}$.

Claim 9: $\sum_{j \in N} x_{j}(e)=\bar{x}$.

Proof. By contradiction, suppose $\sum_{j \in N} x_{j}(e)<\bar{x}$. Then, by $x(e) \in P(e)$ and Remark 1 , for each $j \in N, v_{j}\left(x_{j}(e)+1\right)-v_{j}\left(x_{j}(e)\right)=0$. Since $e^{\prime}$ is the $K$-replica of $e$, there is $j \in N$ such that $R_{j}=R_{i}^{\prime}$ and $x_{j}(e)=x_{i}$. Thus,

$$
v_{i}^{\prime}\left(x_{i}+1\right)-v_{i}^{\prime}\left(x_{i}\right)=v_{j}\left(x_{j}(e)+1\right)-v_{j}\left(x_{j}(e)\right)=0 \text {. }
$$

Therefore, monotonicity and submodularity imply $v_{i}^{\prime}\left(x_{i}\right) \geq v_{i}^{\prime}\left(y_{i}^{*}\right)$, a contradiction.

By Claim 9 and the definition of $x$,

$$
\sum_{j \in N^{\prime}} x_{j}=\sum_{j \in N} K \cdot x_{j}(e)=K \cdot \bar{x}=\bar{x}^{\prime} \geq \sum_{j \in N^{\prime}} y_{j}^{*} .
$$

Thus, by $y_{i}^{*}>x_{i}$, there is $j \in N^{\prime} \backslash\{i\}$ such that $y_{j}^{*}<x_{j}$.

Claim 10: $v_{i}^{\prime}\left(y_{i}^{*}\right)-v_{i}^{\prime}\left(y_{i}^{*}-1\right)=v_{j}^{\prime}\left(y_{j}^{*}+1\right)-v_{j}^{\prime}\left(y_{j}^{*}\right)$.

Proof. We have two cases. 
Case 1: $R_{i}^{\prime}=R_{j}^{\prime}$ and $x_{i}=x_{j}$. We have $y_{i}^{*}>x_{i}=x_{j}>y_{j}^{*}$. Thus, by $y^{*} \in P\left(e^{\prime}\right)$, Remark 2 , $R_{i}=R_{j}$, and submodularity,

$$
\begin{aligned}
v_{i}^{\prime}\left(y_{i}^{*}\right)-v_{i}^{\prime}\left(y_{i}^{*}-1\right) & \geq v_{j}^{\prime}\left(y_{j}^{*}+1\right)-v_{j}^{\prime}\left(y_{j}^{*}\right) \\
& =v_{i}^{\prime}\left(y_{j}^{*}+1\right)-v_{i}^{\prime}\left(y_{j}^{*}\right) \\
& \geq v_{i}^{\prime}\left(y_{i}^{*}\right)-v_{i}^{\prime}\left(y_{i}^{*}-1\right) .
\end{aligned}
$$

Thus, $v_{i}^{\prime}\left(y_{i}^{*}\right)-v_{i}^{\prime}\left(y_{i}^{*}-1\right)=v_{j}^{\prime}\left(y_{j}^{*}+1\right)-v_{j}^{\prime}\left(y_{j}^{*}\right)$.

Case 2: $R_{i}^{\prime} \neq R_{j}^{\prime}$ or $x_{i} \neq x_{j}$. Since $e^{\prime}$ is the $K$-replica of $e$, there is $k \in N$ such that $R_{k}=R_{i}^{\prime}$ and $x_{k}(e)=x_{i}$. For the same reason, there is $\ell \in N$ such that $R_{\ell}=R_{j}^{\prime}$ and $x_{\ell}(e)=x_{j}$. By $x(e) \in P(e)$ and Remark $2, v_{k}\left(x_{k}(e)+1\right)-v_{k}\left(x_{k}(e)\right) \leq v_{\ell}\left(x_{\ell}(e)\right)-v_{\ell}\left(x_{\ell}(e)-1\right)$. Thus,

$$
\begin{aligned}
v_{i}^{\prime}\left(x_{i}+1\right)-v_{i}^{\prime}\left(x_{i}\right) & =v_{k}\left(x_{k}(e)+1\right)-v_{k}\left(x_{k}(e)\right) \\
& \leq v_{\ell}\left(x_{\ell}(e)\right)-v_{\ell}\left(x_{\ell}(e)-1\right) \\
& =v_{j}^{\prime}\left(x_{j}\right)-v_{j}^{\prime}\left(x_{j}-1\right) .
\end{aligned}
$$

By $y^{*} \in P\left(e^{\prime}\right)$ and Remark $2, v_{i}^{\prime}\left(y_{i}^{*}\right)-v_{i}^{\prime}\left(y_{i}^{*}-1\right) \geq v_{j}^{\prime}\left(y_{j}^{*}+1\right)-v_{j}^{\prime}\left(y_{j}^{*}\right)$. Thus, by $y_{i}^{*}>x_{i}$, $y_{j}^{*}<x_{j}$, (1) and submodularity,

$$
\begin{aligned}
v_{i}^{\prime}\left(y_{i}^{*}\right)-v_{i}^{\prime}\left(y_{i}^{*}-1\right) & \geq v_{j}^{\prime}\left(y_{j}^{*}+1\right)-v_{j}^{\prime}\left(y_{j}^{*}\right) \\
& \geq v_{j}^{\prime}\left(x_{j}\right)-v_{j}^{\prime}\left(x_{j}-1\right) \\
& \geq v_{i}^{\prime}\left(x_{i}+1\right)-v_{i}^{\prime}\left(x_{i}\right) \\
& \geq v_{i}^{\prime}\left(y_{i}^{*}\right)-v_{i}^{\prime}\left(y_{i}^{*}-1\right) .
\end{aligned}
$$

Therefore, $v_{i}^{\prime}\left(y_{i}^{*}\right)-v_{i}^{\prime}\left(y_{i}^{*}-1\right)=v_{j}^{\prime}\left(y_{j}^{*}+1\right)-v_{j}^{\prime}\left(y_{j}^{*}\right)$.

Let $y^{\prime} \in A\left(e^{\prime}\right)$ be such that

$$
y_{i}^{\prime}=y_{i}^{*}-1, y_{j}^{\prime}=y_{j}^{*}+1 \text {, and } y_{k}^{\prime}=y_{k}^{*} \text { for each } k \in N \backslash\{i, j\}
$$


By Claim 10, $v_{i}^{\prime}\left(y_{i}^{*}-1\right)+v_{j}^{\prime}\left(y_{j}^{*}+1\right)=v_{i}^{\prime}\left(y_{i}^{*}\right)+v_{j}^{\prime}\left(y_{j}^{*}\right)$. Thus,

$$
\sum_{k \in N^{\prime}} v_{k}^{\prime}\left(y_{k}^{\prime}\right)=v_{i}^{\prime}\left(y_{i}^{*}-1\right)+v_{j}^{\prime}\left(y_{j}^{*}+1\right)+\sum_{k \in N^{\prime} \backslash\{i, j\}} v_{k}^{\prime}\left(y_{k}^{*}\right)=\sum_{k \in N^{\prime}} v_{k}^{\prime}\left(y_{k}^{*}\right)
$$

Thus, by $y^{*} \in P\left(e^{\prime}\right)$, we have $y^{\prime} \in P\left(e^{\prime}\right)$. Moreover, by $y_{i}^{*}>x_{i}$ and $y_{j}^{*}<x_{j}$,

$$
\begin{aligned}
\sum_{k \in N^{\prime}}\left|y_{k}^{\prime}-x_{k}\right| & =\left|y_{i}^{*}-1-x_{i}\right|+\left|y_{j}^{*}+1-x_{j}\right|+\sum_{k \in N^{\prime} \backslash\{i, j\}}\left|y_{k}^{*}-x_{k}\right| \\
& =-2+\sum_{k \in N^{\prime}}\left|y_{k}^{*}-x_{k}\right| \\
& <\sum_{k \in N^{\prime}}\left|y_{k}^{*}-x_{k}\right| .
\end{aligned}
$$

This contradicts the definition of $y^{*}$.

Let

$$
N^{*}:=\left\{j \in N^{\prime}: x_{j}<\bar{x}^{\prime}, v_{j}^{\prime}\left(x_{j}+1\right)-v_{j}^{\prime}\left(x_{j}\right)=p_{\min }\left(e^{\prime}\right)\right\}
$$

Note that $\left|N^{*}\right| \geq K$. Let $i \in N^{\prime}$ and

$$
\begin{aligned}
& N_{1}:=\left\{j \in N^{\prime} \backslash\{i\}: x_{j}\left(e^{\prime}\right)=x_{j}\right\}, \\
& N_{2}:=\left\{j \in N^{\prime} \backslash\{i\}: x_{j}\left(e^{\prime}\right)>x_{j}\right\}, \text { and } \\
& N_{3}:=\left\{j \in N^{\prime} \backslash\{i\}: x_{j}\left(e^{\prime}\right)<x_{j}\right\} .
\end{aligned}
$$

Let $N_{j}^{*}:=N_{j} \cap N^{*}$ for each $j=1,2,3$.

Step 2. $\quad x_{i}\left(e^{\prime}\right) \leq\left|N_{1}^{*}\right|+\sum_{j \in N_{3}^{*}}\left(x_{j}-x_{j}\left(e^{\prime}\right)+1\right)+\sum_{j \in N_{3} \backslash N_{3}^{*}}\left(x_{j}-x_{j}\left(e^{\prime}\right)\right)$.

Proof. Note that $N^{*} \backslash\{i\}=N_{1}^{*} \cup N_{2}^{*} \cup N_{3}^{*}$. Thus, by $\left|N^{*}\right| \geq K$ and $K>\max _{j \in N} x_{j}(e) \geq x_{i}$,

$$
\left|N_{1}^{*}\right|+\left|N_{2}^{*}\right|+\left|N_{3}^{*}\right|=\left|N^{*} \backslash\{i\}\right| \geq x_{i} .
$$


By $N_{2} \supseteq N_{2}^{*}$ and the definition of $N_{2}$,

$$
\left|N_{2}^{*}\right| \leq\left|N_{2}\right| \leq \sum_{j \in N_{2}}\left(x_{j}\left(e^{\prime}\right)-x_{j}\right)
$$

By $x\left(e^{\prime}\right) \in P\left(e^{\prime}\right)$, we have $\sum_{j \in N^{\prime}} x_{j}\left(e^{\prime}\right)=\bar{x}^{\prime}$. By Step $1, \sum_{j \in N^{\prime}} x_{j}=\bar{x}^{\prime}$. Thus,

$$
x_{i}\left(e^{\prime}\right)+\sum_{j \in N_{1}} x_{j}\left(e^{\prime}\right)+\sum_{j \in N_{2}} x_{j}\left(e^{\prime}\right)+\sum_{j \in N_{3}} x_{j}\left(e^{\prime}\right)=\bar{x}^{\prime}=x_{i}+\sum_{j \in N_{1}} x_{j}+\sum_{j \in N_{2}} x_{j}+\sum_{j \in N_{3}} x_{j} .
$$

By $\sum_{j \in N_{1}} x_{j}\left(e^{\prime}\right)=\sum_{j \in N_{1}} x_{j}$ and $\left|N_{2}^{*}\right| \leq \sum_{j \in N_{2}}\left(x_{j}\left(e^{\prime}\right)-x_{j}\right)$,

$$
x_{i}\left(e^{\prime}\right)-x_{i}=\sum_{j \in N_{3}}\left(x_{j}-x_{j}\left(e^{\prime}\right)\right)-\sum_{j \in N_{2}}\left(x_{j}\left(e^{\prime}\right)-x_{j}\right) \leq \sum_{j \in N_{3}}\left(x_{j}-x_{j}\left(e^{\prime}\right)\right)-\left|N_{2}^{*}\right| .
$$

Therefore, by (2) and (3),

$$
\begin{aligned}
x_{i}\left(e^{\prime}\right) & =x_{i}+\left(x_{i}\left(e^{\prime}\right)-x_{i}\right) \\
& \leq\left|N_{1}^{*}\right|+\left|N_{2}^{*}\right|+\left|N_{3}^{*}\right|+\sum_{j \in N_{3}}\left(x_{j}-x_{j}\left(e^{\prime}\right)\right)-\left|N_{2}^{*}\right| \\
& \leq\left|N_{1}^{*}\right|+\left|N_{3}^{*}\right|+\sum_{j \in N_{3}}\left(x_{j}-x_{j}\left(e^{\prime}\right)\right) \\
& \leq\left|N_{1}^{*}\right|+\sum_{j \in N_{3}^{*}}\left(x_{j}-x_{j}\left(e^{\prime}\right)+1\right)+\sum_{j \in N_{3} \backslash N_{3}^{*}}\left(x_{j}-x_{j}\left(e^{\prime}\right)\right) .
\end{aligned}
$$

By Step 2, there is $\left(y_{j}^{*}\right)_{j \in N_{1}^{*} \cup N_{3}} \in X^{\left|N_{1}^{*} \cup N_{3}\right|}$ such that $\sum_{j \in N_{1}^{*} \cup N_{3}} y_{j}^{*}=x_{i}\left(e^{\prime}\right)$ and for each $j \in N_{1}^{*} \cup N_{3}$,

$$
y_{j}^{*} \leq \begin{cases}1 & \text { if } j \in N_{1}^{*}, \\ x_{j}-x_{j}\left(e^{\prime}\right)+1 & \text { if } j \in N_{3}^{*}, \\ x_{j}-x_{j}\left(e^{\prime}\right) & \text { if } j \in N_{3} \backslash N_{3}^{*} .\end{cases}
$$


Let $y \in X^{\left|N^{\prime}\right|}$ be such that for each $j \in N^{\prime}$,

$$
y_{j}= \begin{cases}0 & \text { if } j=i, \\ x_{j}\left(e^{\prime}\right)+y_{j}^{*} & \text { if } j \in N_{1}^{*} \cup N_{3}, \\ x_{j}\left(e^{\prime}\right) & \text { otherwise. }\end{cases}
$$

Note that

$$
\sum_{j \in N^{\prime}} y_{j}=\sum_{j \in N_{1}^{*} \cup N_{3}} y_{j}^{*}+\sum_{j \in N_{-i}^{\prime}} x_{j}\left(e^{\prime}\right)=x_{i}\left(e^{\prime}\right)+\sum_{j \in N_{-i}^{\prime}} x_{j}\left(e^{\prime}\right)=\bar{x}^{\prime}
$$

Thus, $y \in A\left(e^{\prime}\right)$. Moreover, for each $j \in N_{-i}^{\prime}, y_{j} \geq x_{j}\left(e^{\prime}\right)$.

Step 3. Let $j \in N_{-i}^{\prime}$ be such that $y_{j}>x_{j}\left(e^{\prime}\right)$. Let $x_{j}^{\prime} \in\left\{x_{j}\left(e^{\prime}\right)+1, \ldots, y_{j}\right\}$. Then $v_{j}\left(x_{j}^{\prime}\right)-v_{j}\left(x_{j}^{\prime}-1\right)=p_{\min }\left(e^{\prime}\right)$.

Proof. By (i) of Proposition 1, $x_{j}^{\prime}>x_{j}\left(e^{\prime}\right)$, and submodularity,

$$
\begin{aligned}
p_{\min }\left(e^{\prime}\right) & =\max \left\{v_{k}^{\prime}\left(x_{k}\left(e^{\prime}\right)+1\right)-v_{k}^{\prime}\left(x_{k}\left(e^{\prime}\right)\right): k \in N, x_{k}\left(e^{\prime}\right) \neq \bar{x}^{\prime}\right\} \\
& \geq v_{j}^{\prime}\left(x_{j}\left(e^{\prime}\right)+1\right)-v_{j}^{\prime}\left(x_{j}\left(e^{\prime}\right)\right) \\
& \geq v_{j}^{\prime}\left(x_{j}^{\prime}\right)-v_{j}^{\prime}\left(x_{j}^{\prime}-1\right) .
\end{aligned}
$$

Next we show $p_{\min }\left(e^{\prime}\right) \leq v_{j}^{\prime}\left(x_{j}^{\prime}\right)-v_{j}^{\prime}\left(x_{j}^{\prime}-1\right)$. Note that by the definition of $y$ and $y_{j}>x_{j}\left(e^{\prime}\right)$, we have $j \in N_{1}^{*} \cup N_{3}$.

Case 1: $j \in N_{1}^{*}$. By the definition of $y$ and $j \in N_{1}^{*}$, we have $y_{j}=x_{j}\left(e^{\prime}\right)+y_{j}^{*} \leq x_{j}\left(e^{\prime}\right)+1=$ $x_{j}+1$. By $y_{j}>x_{j}\left(e^{\prime}\right)=x_{j}$, we have $y_{j}=x_{j}+1$ and thus, $x_{j}^{\prime}=x_{j}+1$. Thus, by $j \in N^{*}$,

$$
p_{\min }\left(e^{\prime}\right)=v_{j}^{\prime}\left(x_{j}+1\right)-v_{j}^{\prime}\left(x_{j}\right)=v_{j}^{\prime}\left(x_{j}^{\prime}\right)-v_{j}^{\prime}\left(x_{j}^{\prime}-1\right) .
$$

Case 2: $j \in N_{3}^{*}$. By the definition of $y$ and $j \in N_{3}^{*}$, we have $x_{j}^{\prime} \leq y_{j}=x_{j}\left(e^{\prime}\right)+y_{j}^{*} \leq x_{j}+1$. Thus, by $j \in N^{*}$ and submodularity,

$$
p_{\min }\left(e^{\prime}\right)=v_{j}^{\prime}\left(x_{j}+1\right)-v_{j}^{\prime}\left(x_{j}\right) \leq v_{j}^{\prime}\left(x_{j}^{\prime}\right)-v_{j}^{\prime}\left(x_{j}^{\prime}-1\right) .
$$

Case 3: $j \in N_{3} \backslash N_{3}^{*}$. By $N^{*} \neq \emptyset$ and $j \in N_{3} \backslash N_{3}^{*}$, there is $k \in N^{*}$ such that $k \neq j$. Then, 
by $k \in N^{*}, x \in P\left(e^{\prime}\right)$ and Remark 2 ,

$$
p_{\min }\left(e^{\prime}\right)=v_{k}^{\prime}\left(x_{k}+1\right)-v_{k}^{\prime}\left(x_{k}\right) \leq v_{j}^{\prime}\left(x_{j}\right)-v_{j}^{\prime}\left(x_{j}-1\right) .
$$

By the definition of $y, x_{j}^{\prime} \leq y_{j}=x_{j}\left(e^{\prime}\right)+y_{j}^{*} \leq x_{j}$. Thus, by submodularity,

$$
p_{\min }\left(e^{\prime}\right) \leq v_{j}^{\prime}\left(x_{j}\right)-v_{j}^{\prime}\left(x_{j}-1\right) \leq v_{j}^{\prime}\left(x_{j}^{\prime}\right)-v_{j}^{\prime}\left(x_{j}^{\prime}-1\right) .
$$

Step 4. Completing the proof.

By Step 3, for each $j \in N_{-i}^{\prime}$ with $y_{j}>x_{j}$,

$$
\begin{aligned}
v_{j}^{\prime}\left(y_{j}\right)-v_{j}^{\prime}\left(x_{j}\right) & =v_{j}^{\prime}\left(y_{j}\right)-v_{j}^{\prime}\left(y_{j}-1\right)+\left(v_{j}^{\prime}\left(y_{j}-1\right)-v_{j}^{\prime}\left(y_{j}-2\right)\right)+\cdots+\left(v_{j}^{\prime}\left(x_{j}+1\right)-v_{j}^{\prime}\left(x_{j}\right)\right) \\
& =p_{\min }\left(e^{\prime}\right) \cdot\left(y_{j}-x_{j}\left(e^{\prime}\right)\right) .
\end{aligned}
$$

By the definition of $y$,

$$
x_{i}\left(e^{\prime}\right)=\sum_{j \in N_{-i}^{\prime}}\left(y_{j}-x_{j}\left(e^{\prime}\right)\right) .
$$

Thus, we have

$$
\begin{aligned}
s_{i}\left(e^{\prime}\right) & =\max _{x^{\prime} \in A\left(e^{\prime}\right)} \sum_{j \in N_{-i}^{\prime}} v_{j}^{\prime}\left(x_{j}^{\prime}\right)-\sum_{j \in N_{-i}^{\prime}} v_{j}^{\prime}\left(x_{j}\left(e^{\prime}\right)\right) \\
& \geq \sum_{j \in N_{-i}^{\prime}} v_{j}^{\prime}\left(y_{j}\right)-\sum_{j \in N_{-i}^{\prime}} v_{j}^{\prime}\left(x_{j}\left(e^{\prime}\right)\right) \\
& =\sum_{j \in N_{-i}^{\prime}}\left(v_{j}^{\prime}\left(y_{j}\right)-v_{j}^{\prime}\left(x_{j}\left(e^{\prime}\right)\right)\right) \\
& =p_{\min }\left(e^{\prime}\right) \cdot \sum_{j \in N_{-i}^{\prime}}\left(y_{j}-x_{j}\left(e^{\prime}\right)\right) \\
& =p_{\min }\left(e^{\prime}\right) \cdot x_{i}\left(e^{\prime}\right) \\
& =t_{i}\left(e^{\prime}\right) .
\end{aligned}
$$

On the other hand, by Fact 4, $s_{i}\left(e^{\prime}\right) \leq t_{i}(e)$. Hence, $s_{i}\left(e^{\prime}\right)=t_{i}\left(e^{\prime}\right)$. 


\section{References}

Ausubel, Lawrence M, Peter Cramton, Marek Pycia, Marzena Rostek, and Marek Weretka (2014) "Demand reduction and inefficiency in multi-unit auctions," Review of Economic Studies, 84, 1366-1400.

Azevedo, Eduardo M. and Eric Budish (2015) “Strategy-proofness in the large," Chicago Booth Research Paper.

Baisa, Brian (2015) "Bid behavior in the uniform price and vickrey auctions on a general preference domain," mimeo.

Bodoh-Creed, Aaron (2013) "Efficiency and information aggregation in large uniformprice auctions," Journal of Economic Theory, 148, 2436-2466.

Che, Yeon-Koo and Fuhito Kojima (2010) "Asymptotic equivalence of probabilistic serial and random priority mechanisms," Econometrica, 78, 1625-1672.

Che, Yeon-Koo, Jinwoo Kim, and Fuhito Kojima (2015) "Stable matching in large economies," Working paper.

Che, Yeon-Koo and Olivier Tercieux (2015) "Efficiency and stability in large matching markets," Working paper.

Cripps, Martin W. and Jeroen M. Swinkels (2006) "Efficiency of large double auctions," Econometrica, 74, 47-92.

Foley, Duncan (1967) "Resource allocation and the public sector," Yale Economic Essays, 7, 45-98.

Fudenberg, Drew, Markus Mobius, and Adam Szeidl (2007) "Existence of equilibrium in large double auctions," Journal of Economic Theory, 133, 550-567.

Gul, Faruk and Enio Stacchetti (1999) "Walrasian equilibrium with gross substitutes," Journal of Economic Theory, 87, 95-124. 
Immorlica, Nicole and Mohammad Mahdian (2005) "Marriage, honesty, and stability," In Proceedings of the Sixteenth Annual ACM-SIAM Symposium on Discrete algorithms, $53-62$.

Jackson, Matthew O. and Ilan Kremer (2006) "The relevance of a choice of auction format in a competitive environment," Review of Economic Studies, 73, 961-981.

Jackson, Matthew O. and Alejandro M. Manelli (1997) "Approximately competitive equilibria in large finite economies," Journal of Economic Theory, 77, 354-376.

Kelso, Alexander S. and Vincent P. Crawford (1982) "Job matching, coalition formation, and gross substitutes," Econometrica, 50, 1483-1504.

Kojima, Fuhito and Parag. A. Pathak (2009) "Incentives and stability in large two-sided matching markets," American Economic Review, 99, 608627.

Lee, SangMok (2015) "Incentive compatibility of large centralized matching markets," Working paper.

Otani, Yoshihiko and Joseph Sicilian (1982) "Equilibrium allocations of Walrasian preference games," Journal of Economic Theory, 27, 47-68.

Otani, Yoshihiko and Joseph Sicilian (1990) "Limit properties of equilibrium allocations of Walrasian strategic games," Journal of Economic Theory, 27, 295-312.

Roberts, Donald John and Andrew Postlewaite (1976) "The incentives for price-taking behavior in large exchange economies," Econometrica, 44, 115-127.

Swinkels, Jeroen M. (1999) "Asymptotic efficiency for discriminatory private value auctions," Review of Economic Studies, 66, 509-528.

Swinkels, Jeroen M. (2001) "Efficiency of large private value auctions," Econometrica, 69, 37-68. 